\title{
Communication and electronic access - medical radiation science climical centres' perspective
}

\author{
DG Lyall, Y Surjan \\ Discipline of Medical Radiation Science (MRS), The Hunter Building, The University of Newcastle, \\ Callaghan, New South Wales 2308, Australia. \\ Correspondence David.Lyall@newcastle.edu.au
}

\begin{abstract}
Alstract The last decade has seen a dramatic increase in the availability and use of electronic devices and information in day-to-day lives and in the workplace. The tertiary education sector has embraced the electronic age and has, in our cases, taken the lead with innovative use of information technology (IT). While the flexibility IT provides appeals to students and creates new opportunities, the IT infrastructure and staff development required to make full use of the new facilities requires significant investment. The aim of this study was to survey medical radiation science professional centres to assess the availability of IT resources, determine who has access to the IT resources and sample staff attitudes towards their preferred method of communication with the university. A questionnaire was mailed to each Chief Nuclear Medicine Scientist, Chief Radiation Therapist and Chief Radiographer for each clinical centre that participated in The University of Newcastle's clinical placement program (PPS). One hundred and thirty one questionnaires were returned, a response rate of $51 \%$. Twenty-seven responses from nuclear medicine centres $(50 \%)$, twenty-four responses from radiation therapy centres $(70 \%)$ and 80 responses from diagnostic radiography centres (48\%). The majority $(85 \%)$ of respondents reported they had between three and 30 computers where staff could access the internet, word processing and email. The preferred method of communication was email (52\%) versus letter $(30 \%)$ and telephone (17\%). In the event that work load increased, email was a preferred method of communication where the preference for telephone and letters decreased.
\end{abstract}

Keywords: communication, clinical information technology, electronic access, flexibility, technology

\section{Introduction}

The last decade has seen a dramatic increase in the availability and use of electronic devices and information in the day-to-day lives of many people. This has also been the case in many places of employment where the internet provides an almost endless supply of information and a very popular and efficient means of communication. ${ }^{1}$ The tertiary education sector has equally embraced the electronic age and in some cases taken the lead with innovative use of technology. ${ }^{1}$ Examples range from online courses which are commonplace today but were cutting edge a decade ago to pod-casting lectures and live web casting between multiple centres where students may communicate in real time and function as effectively as if they were in a single lecture room.

While the flexibility appeals to students and creates new opportunities, ${ }^{1}$ the IT infrastructure and staff development to utilise the new facilities requires significant investment. ${ }^{2,3}$ Consequently, in recognition of the growing trend of IT resources in the workplace and the educational advantages IT can facilitate, ${ }^{4}$ The University of Newcastle has committed to investing in the next generation of the professional placements management software. It is expected that this system will enable improved communication between clinical centres, the university and students.

Currently the Medical Radiation Science (MRS) programs, Nuclear Medicine (NM), Radiation Therapy (RT) and Diagnostic Radiography (DR), at The University of Newcastle utilise the professional placements management system (PPS) to assist in conducting two block clinical placements per student per year for each of the three years. This equates to approximately 700 individual student block placements per year. Therefore, IT provides an attractive tool to assist with the block clinical placement process.

Despite the many advantages of the PPS and its IT foundations, the ultimate success of the next generation of the professional placements system or similar systems developed by other universities to manage MRS or other professional clinical placements depends on a number of factors:

Uptake: How much IT infrastructure do NM, RT or DR centres have available?

Access: Who has access and how readily?

Preference: What medium do MRS professionals prefer to communicate to the Universities through, email, phone or letter?

In a bid to increase the effectiveness of our current communication with clinical centres and respective students, a need to identify the answers to the previous issues was recognised. To better understand the requirements and preferences of clinical centres we have conducted a survey to assess these factors.

\section{Methods}

A questionnaire was mailed to each Chief Nuclear Medicine Scientist, Chief Radiation Therapist and Chief Radiographer for each clinical centre that participated in The University of Newcastle's clinical placement program. 


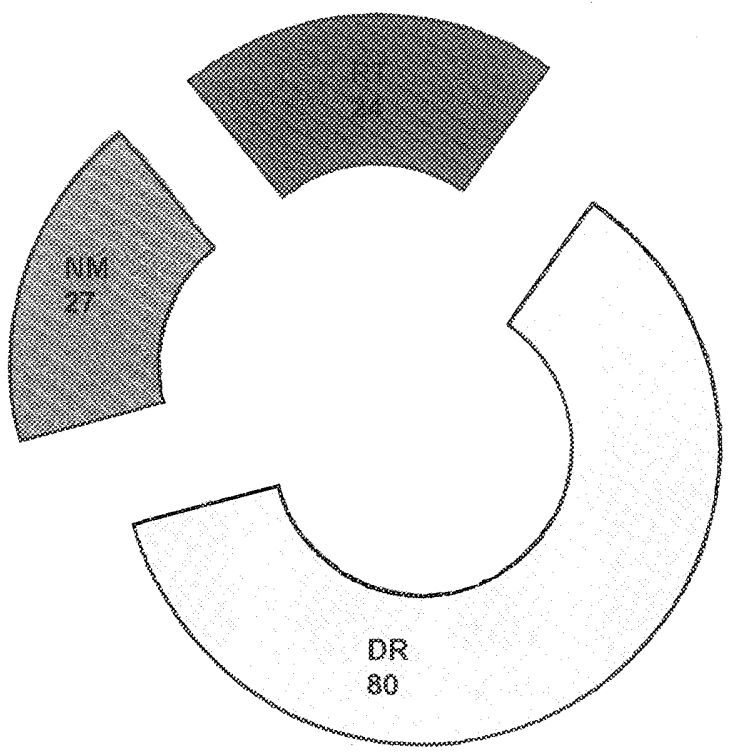

Figere 1: Response rates for nuclear medicine, radiation therapy and diagnostic radiography clinical centres.



Figure 3: Currently available information technology within departments.

The questionnaire consisted of a series of questions to examine the level of uptake of IT resources available in their department and if there was a plan in place to upgrade the level of resources in the upcoming 12 months. The questionnaire also examined who had access to the available IT resources and how frequently each category of staff would access them. The third area examined by the questionnaire was the preferred method of communication with the university, whether it is telephone, letter or email.

\section{Resallits}

The response rate was $51 \%$, with 131 questionnaires returned. The response rate from radiation therapy centres was 24 questionnaires returns $(70 \%)$, followed by 27 responses from nuclear medicine centres $(51 \%)$ and 80 responses from diagnostic radiography centres $(48 \%)$.

Initial analysis of the data did not show any significant variation between the three MRS professions (nuclear medicine, radiation therapy and diagnostic radiography). Therefore the data was analysed as a single grouped data set.

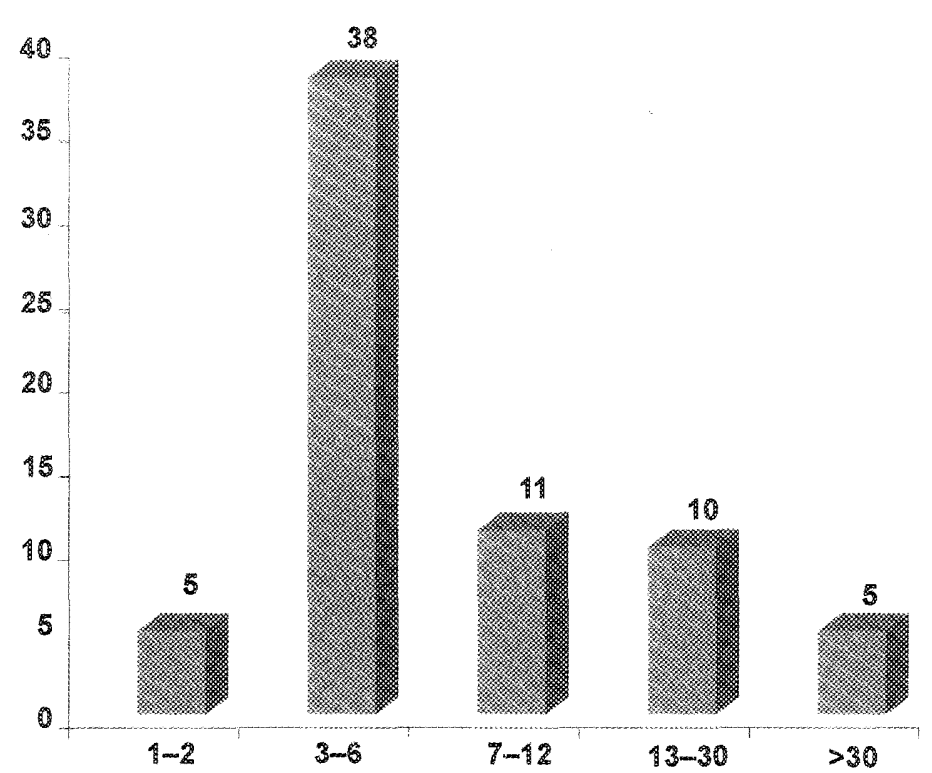

Figure 2: Number of computers per department.

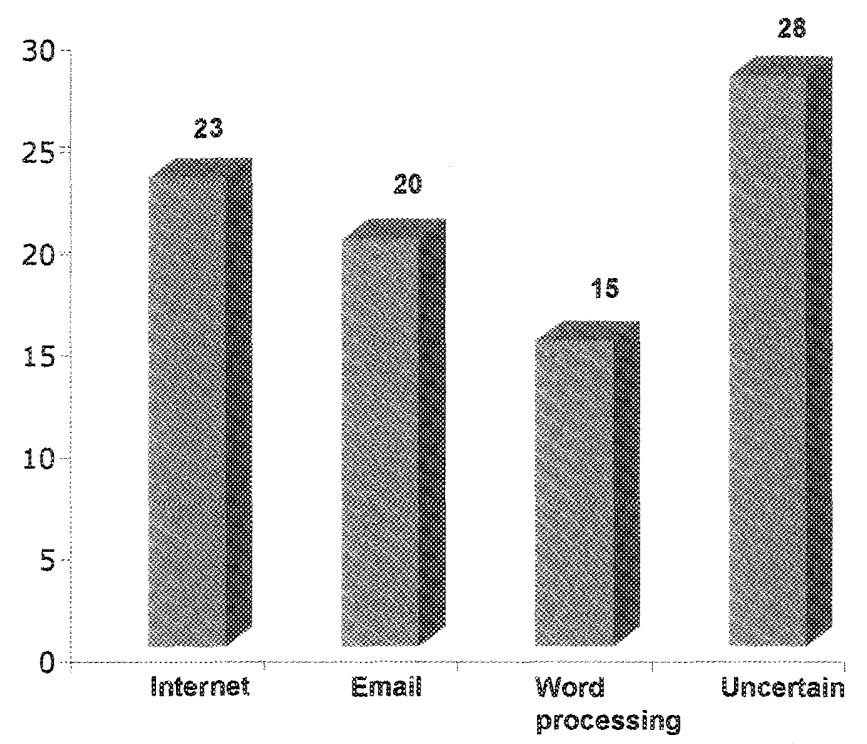

Figure 4: Future upgrades.

\section{Computers in the workplace}

Every respondent indicated they had at least one computer where staff could access the internet, word processing and/or email. A reported $85 \%$ of responses confirmed to have a total in the range of three to 30 computers. Five centres reported they had greater than 30 computers.

\section{Intermet, word processing or email}

A total of $96 \%$ of respondents had access to work related word processing, 92\% had access to work related email and $89 \%$ had access to work related internet. The majority of centres (84\%) reported they had access to work related internet, word processing and email. The remaining $16 \%$ of centres had access to only work related internet or a combination of internet and word processing or email.

\section{Upgrade}

Of the centres participating in the questionnaire, $19 \%$ responded they would be upgrading internet, word processing and email facilities in the next twelve months. A further $35 \%$ responded they would be upgrading one or two of these tools in the same period. 


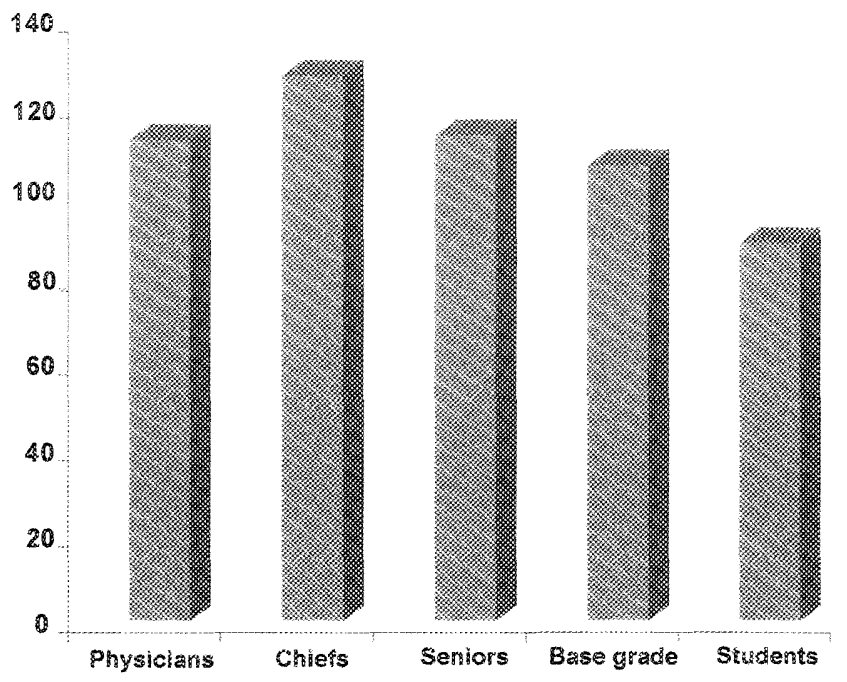

Figure 5: Staff with access to information technology.

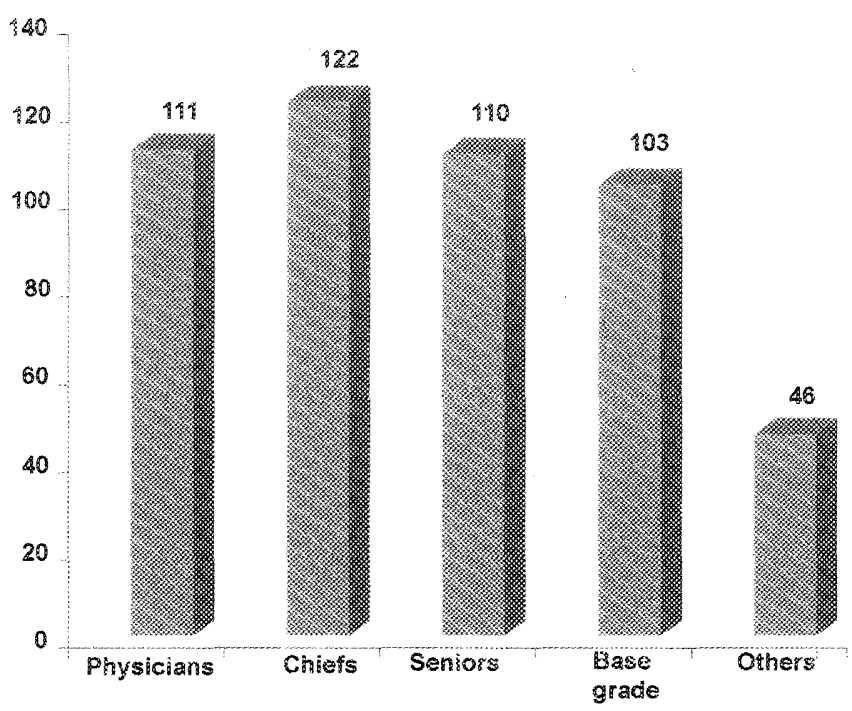

Figure 6: Staff who should have access.

Table 1 : Frequency of access.

\begin{tabular}{|c|c|c|c|c|c|c|}
\hline & Twice daily & Once daily & Hwice weekly & Once weekly & Twice monthily & Once monthly \\
\hline Physicians & 84 & 14 & 3 & 1 & 0 \\
\hline Chief & 98 & 15 & 2 & 1 & 0 \\
\hline Seniors & 61 & 26 & 7 & 6 & 0 & 0 \\
\hline DR/NM/RT & 37 & 28 & 15 & 13 & 0 \\
\hline Students & 26 & 31 & 7 & 8 & 0 & 0 \\
\hline Other & 23 & 5 & 2 & 2 & 0 & 0 \\
\hline
\end{tabular}

Responses from $46 \%$ of centres expressed they were uncertain if they would undertake any upgrade in the next twelve months.

\section{Current access}

Nuclear medicine specialists, radiation oncologists and radiologists were reported to have IT resource access in $112(85 \%)$ of centres. Chiefs in respective professions reported access in $97 \%$ of centres while seniors were reported to have access in $86 \%$ of centres. Base grade staff reported access in $81 \%$ of centres, and finally students reported access in $67 \%$ of centres.

\section{Respondents' opinion of access}

This question examined the respondents' opinion of who should have access to IT resources for internet, word processing and email as opposed to who currently does have access.

Nuclear medicine specialists, radiation oncologists and radiologists were reported to have IT resource access in $111(85 \%)$ of centres. Chiefs in respective professions reported access in $93 \%$ of centres while senior staff were reported to have access in $84 \%$ of centres. Base grade staff reported access in $78 \%$ of centres and students reported access in $35 \%$ of centres. Respondents reported other professions who they considered should have IT access including nurses, clerical staff, physicists or engineers.

\section{Frequency of access}

The respondents reported that $96 \%$ of specialists would access the IT resources for work related internet, word processing and/or email once or twice per day, while the remainder would access the resources once or twice per week.

Chiefs reported a similar level of access at $97 \%$ accessing IT resources once or twice per day. However, this trend appears to decline with senionity where $87 \%$ of staff classified as seniors and $68 \%$ of base grade level staff were reported to access IT services daily. Interestingly, centres reported $79 \%$ of students and $88 \%$ of 'other staff' would access IT resources daily.

\section{Preferred method of communication}

The data clearly ranked respondents' preferred method of communication with email being the most popular at $52 \%$, followed by written correspondence at $30 \%$ and telephone communication at $17 \%$. Respondents were then asked to list their preferred method of communication if their work load were to change. If their workload were to increase, $58 \%$ of respondents indicated email as their preferred method followed by $29 \%$ for written correspondence and $14 \%$ for telephone contact. If the situation were to be reversed and the respondents' workload decreased then email remained the most popular method of communication at $52 \%$, written correspondence decreased to $29 \%$ and telephone communication increased marginally to $19 \%$.

\section{Discussion}

The level of IT infrastructure is high with $85 \%$ of respondents reporting they have three to 30 computers within their department. It may be assumed that this will increase as $35 \%$ of respondents have indicated they plan to upgrade their IT infrastructure in the next twelve months. Overall, the data has shown that specialists have high levels of access, however in the context of PPS or similar systems, chiefs and senior staff have comparatively high levels of access ranking at $97 \%$ and $86 \%$ respectively. This level of access is key to the success of PPS as chiefs and seniors are likely to be responsible for the supervision of students on 


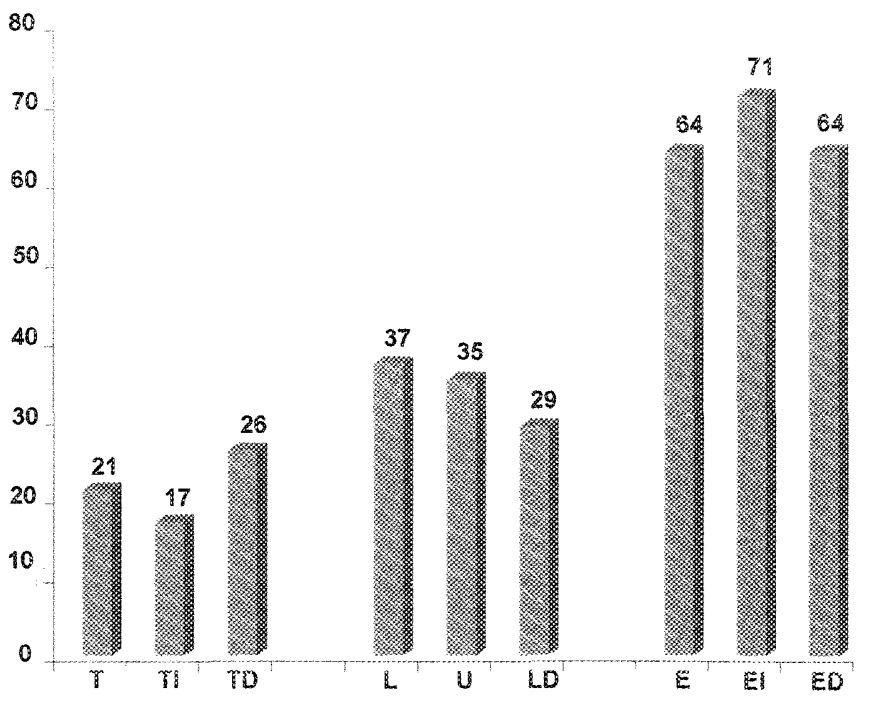

Figure 7: First preferences versus work increase and decrease for telephone, letter and email use. $\mathrm{T}=$ Telephone, $\mathrm{TI}=$ Telephone increased workload, $\mathrm{TD}=$ Telephone decreased workload, $L=$ Letter, $L I=$ Letter increased workload, $L D$ $=$ Letter decreased workload, $\mathrm{E}=$ Email, EI $=$ Email increased workload, $E D=$ Email decreased workload.

placement and communication with the various universities.

The results of the survey reveal email to be the preferred method of communication at $52 \%$ and written correspondence and telephone at $30 \%$ and $17 \%$ respectively. The project considered that individuals would have a personal preference for the method of communication and asked if this preference would change if their workload was to increase or decrease. While there was some minor change in preferences, this typically ranged from zero to $6 \%$ dependent on the method and increase or decrease of workload. The data indicates that most respondents held to their original preferences and were not attracted to more efficient methods of communication by changes in their workload. Despite the high levels of IT infrastructure and high levels of access, individuals' adherence to a personal preference for certain methods of communication may make the task of implementing PPS or equivalent systems challenging.

\section{Conclusion}

The factors required for the successful implementation of the next generation of the PPS may be classified as the uptake of IT resources, access for clinical staff to the IT resources and a preference by clinical staff to communicate via email.

The current level of IT infrastructure is high, the capabilities of this infrastructure and the fact that nearly half of centres intend to upgrade will further enhance IT resources available to all levels of staff from specialists to base grade staff (even students in $67 \%$ of centres currently have access). Coupled with the large percentage of centres $(52 \%)$ who have indicated email is their preferred method of communication, centres are increasingly strengthening their position in order to take advantage of technology to freely and efficiently communicate with universities and other clinical centres.

It is therefore reasonable to conclude that the next generation of PPS would be well received by Medical Radiation Science Clinical Centres based on their current levels of IT resources, high levels of staff access to the IT resources and the significant preference for email as their preferred method of communication.

\section{Acknowledgements}

The authors would like to thank the contributions of the clinical centres in the collection of the electronic access information survey.

\section{References}

1 Simon, H. Expert decision making and the managerial future. Monash Mt Eliza Business Review 1998; 1: 30-7.

2 Belanger, Y. Program Evaluator. Centre for Instructional Technology, Duke University 2005-2006 Initiative. Available online at www.duke.edu.ipod/ about/faculty.html [verified May 2007].

3 Saade, R.G, Kira, D. Mediating the Impact of Technology Usage on Perceived Ease of Use Anxiety. J Comp Edu 2007; 49 (4): 1189-1204.

4 Kluge, M.A, Glick, L. Teaching Therapeutic Communication via camera cues and clues: The video inter-active method. $J$ Nurs Edu 2006; 45 (11): 463-71. 